\title{
Changes in bird communities following conversion of lowland forest to oil palm and rubber plantations in southern Thailand
}

\author{
SIRIRAK ARATRAKORN, SOMYING THUNHIKORN and PAUL F. DONALD
}

\section{Summary}

This paper describes changes in bird communities following the conversion of lowland forest to commercial oil palm and rubber plantations. Conversion of forest to plantations resulted in a reduction in species richness of at least $60 \%$, with insectivores and frugivores suffering greater losses than more omnivorous species. Of the 128 species recorded across all habitats, $84 \%$ were recorded in forest, and $60 \%$ were recorded only in that habitat. Of the 16 Globally Threatened or Near-Threatened species recorded in the study, 15 were recorded only in forest. Species occurring in plantations were significantly more widespread in Thailand than species recorded only in forests and had a tendency towards smaller body size. Species richness in plantations was unaffected by plantation age or distance from nearest forest edge, but was significantly greater where undergrowth was allowed to regenerate beneath the crop trees. Bird communities in oil palm and rubber plantations were extremely similar, and there was a strong positive correlation across species in their relative abundance in each plantation type. The results indicate that a high proportion of species formerly present in the region are unable to adapt to conversion of forest to oil palm and rubber plantations, resulting in large losses of bird species and family richness and the replacement of species with restricted ranges and high conservation status by those with extensive ranges and low conservation status. Initiatives that reduce pressure to clear new land for plantations, for example by increasing productivity in existing plantations and improving protected area networks, are likely to be more effective in conserving threatened forest birds than initiatives to improve conditions within plantations, though both should be encouraged.

\section{Introduction}

The loss of tropical forests, and particularly of lowland forests, represents one of the greatest threats to bird diversity globally (e.g. BirdLife International 2004, Niesten et al. 2004). The greatest single cause of deforestation is the clearance of land for agriculture, which is proceeding most rapidly in countries with the highest biodiversity (Balmford and Long 1994) and at a higher rate in areas holding restricted range bird species than outside them (Scharlemann et al. 2004). Losses of tropical forest to agriculture are likely to continue. In the developing world, 109 hectares of pristine habitats, an area approximately equal to that of all the planet's remaining tropical rainforests (Mayaux et al. 1998), may be cleared for agriculture by 2050 (Tilman et al. 2001). Two of the most rapidly expanding crops in tropical regions are oil palm Elaeis guineensis and rubber Hevea brasiliensis (Clay 2004). The global area of oil palm production nearly tripled between 1961 and 2000, most of this increase 
at the expense of natural habitats, ${ }^{1}$ and per capita consumption of vegetable oils increased more rapidly than any other food during the same period (Clay 2004). The highest rate of oil palm expansion has been in South-East Asia, particularly Malaysia, Indonesia and Thailand, where the area more than doubled in the 10 years from 1995 to 2004. Oil palm now covers at least 10 million hectares globally and is the world's second largest source of edible oils, after soybean Glycine max. In Malaysia, oil palm is the second largest export earner and makes up 56\% of the country's tree cover. Rubber has also increased greatly at the expense of natural habitats, again mainly lowland tropical forest, approximately doubling in area between 1960 and 2000. Once again, South-East Asia dominates production, with Indonesia, Malaysia and Thailand being the world's largest producers. In Thailand, the area of rubber quadrupled between 1960 and 2000. Current high prices for both oil palm and rubber, combined with some aggressive and often subsidised national strategies to increase production (Wu et al. 2001, Clay 2004), mean that expansion of both crops is likely to increase in the near future. This poses a severe threat to the few remaining lowland forests in one of the world's most biodiverse regions. The areas most suitable for oil palm and rubber production lie in the tropical lowlands $10^{\circ}$ either side of the equator. Lowland South-East Asia, where the spread of these crops has been greatest, is a region of particularly high biodiversity and one supporting some of the world's most threatened forests (Lambert and Collar 2002). The Sundaic lowland forests, confined to the ThaiMalay Peninsula and the Greater Sunda islands, have suffered catastrophic losses of area in all range states (except Myanmar), largely because of the spread of oil palm and rubber.

Across a range of agricultural systems, there is a general pattern of biodiversity loss when natural habitats are converted to agricultural ones, and a further loss of biodiversity as such systems are intensified (Donald 2004). However, despite the widely publicised threat posed to biodiversity by oil palm and rubber plantations, remarkably few empirical studies have documented biodiversity change following forest conversion to commercial plantations of these crops. The few published comparisons of biodiversity in tropical plantations and pristine habitats, summarized in Donald (2004), suggest that rubber and oil palm plantations are particularly poor habitats for wildlife and offer little environmental compensation for forest loss. The most detailed study to date was that of Danielsen and Heegaard (1995), who documented the almost complete loss of most vertebrate taxa as forest was converted to oil palm. Similarly, Chung et al. (2000) found that beetle populations were far lower in oil palm than in a range of other natural and agricultural habitats. While most taxa appear to be adversely affected, some are capable of using rubber and oil palm plantations. Wild pigs Sus scrofa reach very high densities in lowland forest surrounding oil palm plantations in Malaysia, at least partly because they feed on the abundant fallen oil palm fruit (Ickes 2001), and White-faced monkeys Cebus capucinus inhabiting agricultural landscapes in Central America feed largely on oil palm fruit (Williams and Vaughan 2001). However, the few empirical studies available suggest that any such gains are greatly outweighed by losses, particularly where crops

\footnotetext{
${ }^{1}$ Areas of crops cited in this paper are derived from the FAOSTAT database of the Food and Agriculture Organization of the United Nations (http://apps.fao.org/)
} 
are grown in intensive monocultures. Empirical evaluation of the effects of conversion of forest to plantations is clearly important if the true environmental effects of plantations are to be quantified and accounted for in global biodiversity inventories and strategies.

This paper describes the results of research undertaken in southern Thailand to estimate and quantify avifaunal change following the replacement of forest by oil palm and rubber plantations, and to assess the effects of vegetation structure and distance from forest patches on bird communities within plantations. This was undertaken as part of a research project designed to support efforts to save the small Thai population of the Critically Endangered Gurney's Pitta Pitta gurneyi, a Sundaic lowland forest endemic species threatened by loss of forests to oil palm and rubber plantations (BirdLife International 2001).

\section{Methods}

Study site and data collection

Fieldwork was undertaken in and around Khao Pra-Bang Khram Wildlife Sanctuary and Bang Khram National Reserve Forest in Krabi Province, peninsular Thailand. The Wildlife Sanctuary and the Forest Reserve contain remnants of the lowland forests that once covered much of peninsular Thailand but have now largely disappeared. Most of the forest loss in the areas around Khao Pra-Bang Khram has been caused by legal and illegal conversion of forest to commercial plantations of rubber and oil palm, largely within the last 20 years. Most recent clearances have been for oil palm planting, although some new rubber plantations are also being established. All counts were undertaken within a $10 \mathrm{~km}$ radius of the Khao Pra-Bang Khram Wildlife Sanctuary headquarters (Figure I).

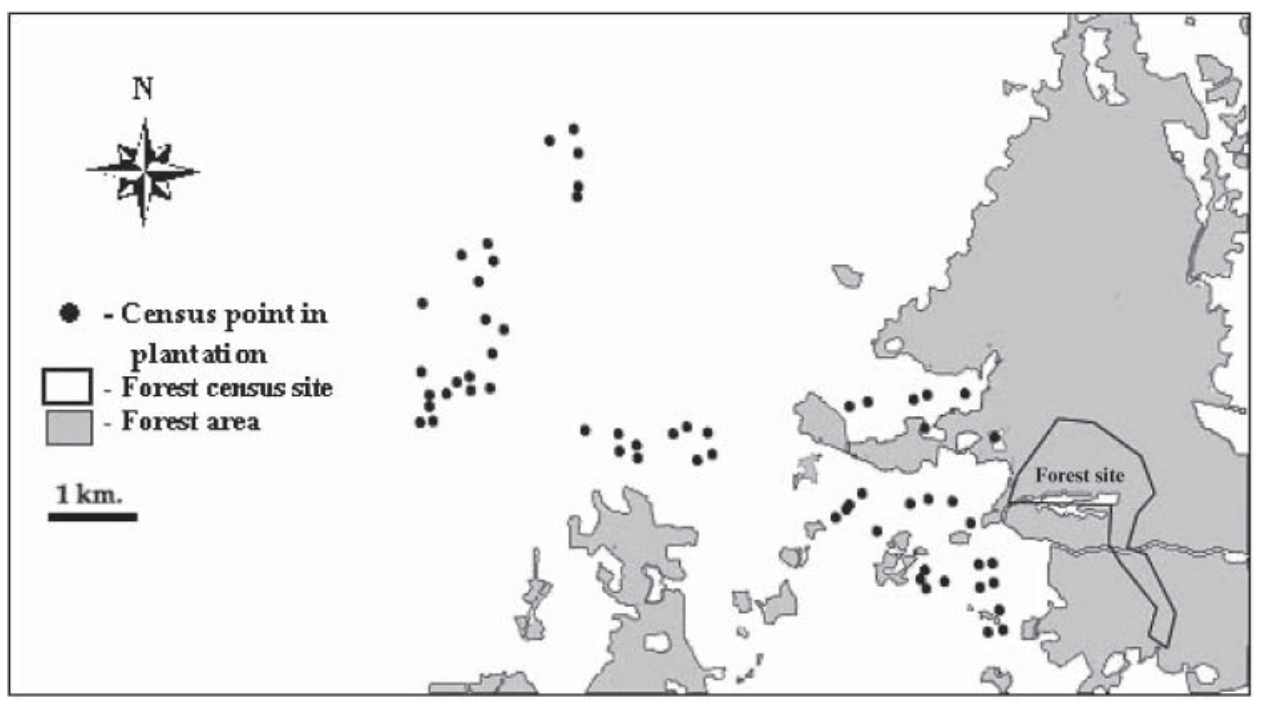

Figure 1. Distribution of census points. Exact location of forest census sites could not be plotted because GPS signals in forest were too weak to allow locations to be recorded. 
Timed Species Counts (TSCs; e.g. Pomeroy and Dranzoa 1997, Bibby et al. 2000, Freeman et al. 2003) were used to collect data on bird species richness and relative abundance. This method was chosen in preference to distance sampling methods because of the difficulty in judging distances in forest, the potentially confounding effects on density estimates of mobile mixed-species flocks, and because estimates of species richness and composition and relative abundance were considered sufficient to assess the major gradients in bird communities in each habitat type. The TSCs were converted to measures of relative abundance, $\lambda$, using the method of Freeman et al. (2003). A total of 30 oil palm plantations and 30 rubber plantations were selected using aerial photographs of the area. This sample size was determined by undertaking a small number $(n=5)$ of preliminary counts in each habitat and using the formula:

$$
M+=\left(\frac{200}{Q}\right)^{2}\left(\frac{s}{N_{1}}\right)^{2}\left(1+\frac{2}{M_{1}}\right)
$$

(where $M+$ is the number of additional sample units needed, $Q$ is the required Percentage Relative Precision, $s$ is the standard deviation from a preliminary sample, $N_{1}$ is the mean number of species recorded in preliminary sample and $M_{1}$ is the number of sample units in a preliminary sample) to estimate the sample size required to achieve a Percentage Relative Precision of species richness of 10\% (i.e. the $95 \%$ CLs fall within $10 \%$ of the mean). These initial counts suggested that a sample size of around 30 would be sufficient to meet this predetermined level of precision, though the non-normality of the response variable might influence the level of precision actually achieved. Two counts, separated by at least 4 weeks, were made between 3 February and 27 March 2004 from points located in the centre of each plantation, and at 30 widely scattered points within the adjacent forest. Counts were undertaken between 06 hoo and Iohoo. Points were sufficiently far apart that individual birds could not be recorded from more than one location, although exact distances could not be measured as portable GPS units worked infrequently in forest. Counts lasted 20 minutes, and were broken into five 4-minute blocks. The first time each species was detected, it was entered on field recording forms in the appropriate 4-minute block. As well as recording the plantation type, a score of undergrowth density was collected, recorded as a binary variable o (little or absent) or I (dense and extensive). Due to the lack of adequate maps and poor functioning of portable GPS units, distance of each plantation from the nearest forest edge was also recorded as a binary variable, indicating whether the plantation was within or beyond $1 \mathrm{~km}$ from the nearest forest.

\section{Data analysis}

Generalized linear models were used to derive estimates of species richness and their standard errors for each habitat type and to test the null hypothesis that species richness was equal in all habitat types. In the case of the plantations, similar models were used to assess the effects on species richness of undergrowth structure, plantation age and type and distance from forest edge. Models assumed a Poisson distribution of errors and a log-link function was specified. Minimum adequate models were derived by sequential backwards deletion from the maximal model. Results are graphically represented as non-parametric boxplots, as these visually convey more information about the distribution of Poisson data than do plots of means and their 
associated error bars and avoid problems such as error bars spanning proportions of o or 1 (Crawley 2002).

We used the general and well-documented relationship between range size and population size (e.g. Gaston et al. 2000, He et al. 2002, Selmi and Boulinier 2004), and between range size and extinction likelihood (e.g. BirdLife International 2004), to use an estimate of the range of each species in Thailand as a surrogate estimate of its relative population size and conservation importance. The assumption was made that species with very extensive ranges in Thailand are more likely to be of lower conservation concern than species with more restricted ranges. Further assumptions about habitat specificity might also be inferred from estimates of range size (e.g. Gregory and Gaston 2000). No systematic data on range size, such as ornithological atlas data, or on population size exist for birds in Thailand, so we estimated relative range size from the maps in Robson (2002), using a transparent graticule. Range was expressed as the proportion of 20 equal-sized cells that overlapped at least partly with the depicted range. Only breeding ranges were included in these analyses, thereby excluding a number of species that only winter in Thailand. Body size (length) was extracted from the same source. We then tested the null hypothesis that species inhabiting plantations and forests have equal average range sizes in Thailand and body sizes using non-parametric tests. Each species was classified into one of a number of foraging guilds based on information in Fogden (1971), Wong (1986) and Wells (1999), and followed the 1o classes identified by Wong (1986). For species included in none of these sources, categorization was based upon the authors' field experience.

\section{Results}

Species accumulation curves (Figure 2) suggest that 20 minutes were sufficient to record most species in plantations but that species richness in forest might be

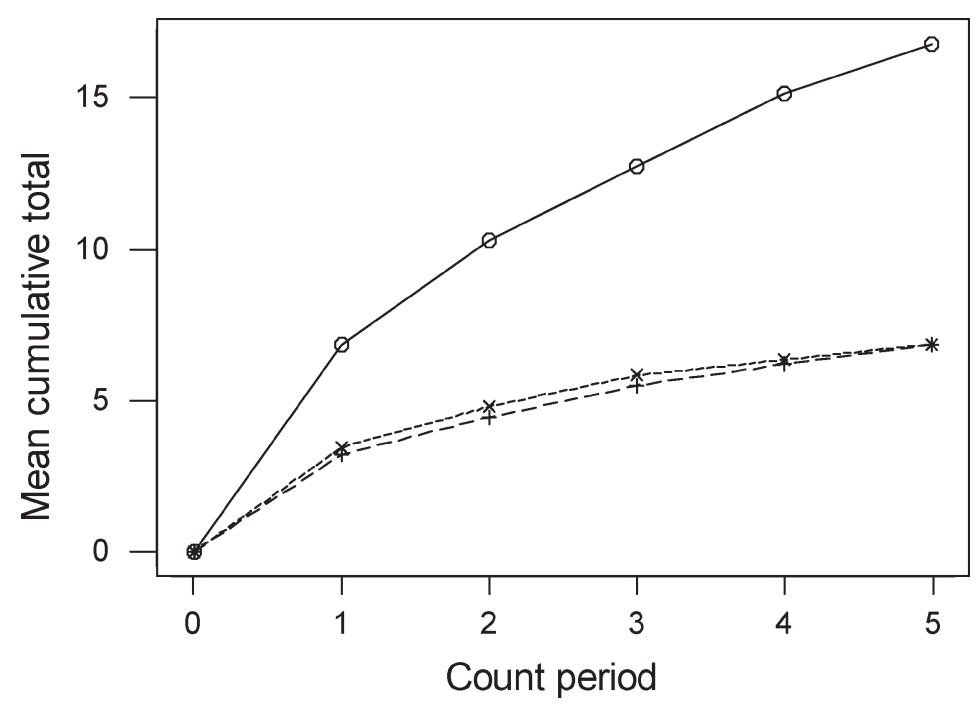

Figure 2. Accumulation rates of species detection across 4-minute count periods in single 2o-minute counts. Unbroken line, forest; dashed line, rubber, dotted line, oil palm. 
Table 1 . Species richness and, in parentheses, overall relative abundance, $\lambda$, of birds in different feeding guilds (following Wong 1986).

\begin{tabular}{lccc}
\hline Guild & Forest & Oil palm & Rubber \\
\hline Insectivores & & & \\
Bark-gleaning insectivore $(n=4)$ & $4(<0.01)$ & $0(0.0)$ & $0(0.0)$ \\
Tree foliage-gleaning insectivore $(n=36)$ & $32(0.16)$ & $9(0.06)$ & $10(0.05)$ \\
Flycatching insectivore $(n=17)$ & $15(0.03)$ & $3(<0.01)$ & $4(<0.01)$ \\
Litter-gleaning insectivore $(n=14)$ & $11(0.03)$ & $3(0.01)$ & $6(0.03)$ \\
Shrub foliage-gleaning insectivore $(n=6)$ & $5(0.05)$ & $3(0.03)$ & $3(0.06)$ \\
Mixed diet & & & \\
Nectarivore/insectivore $(n=12)$ & $9(0.05)$ & $10(0.11)$ & $5(0.06)$ \\
Insectivore/frugivore $(n=17)$ & $14(0.15)$ & $8(0.09)$ & $9(0.08)$ \\
Other & $5(0.01)$ & $4(0.01)$ & $3(<0.01)$ \\
Predator $(n=8)$ & $13(0.16)$ & $\mathbf{1}(<0.01)$ & $\mathbf{1}(<0.01)$ \\
Frugivore $(n=14)$ & $\mathbf{1 0 8 ( 0 . 6 4 )}$ & $\mathbf{4 1 ( 0 . 3 2 )}$ & $\mathbf{4 1}(\mathbf{0 . 2 8})$ \\
Total $(\boldsymbol{n}=\mathbf{1 2 8})$ & & & \\
\hline
\end{tabular}

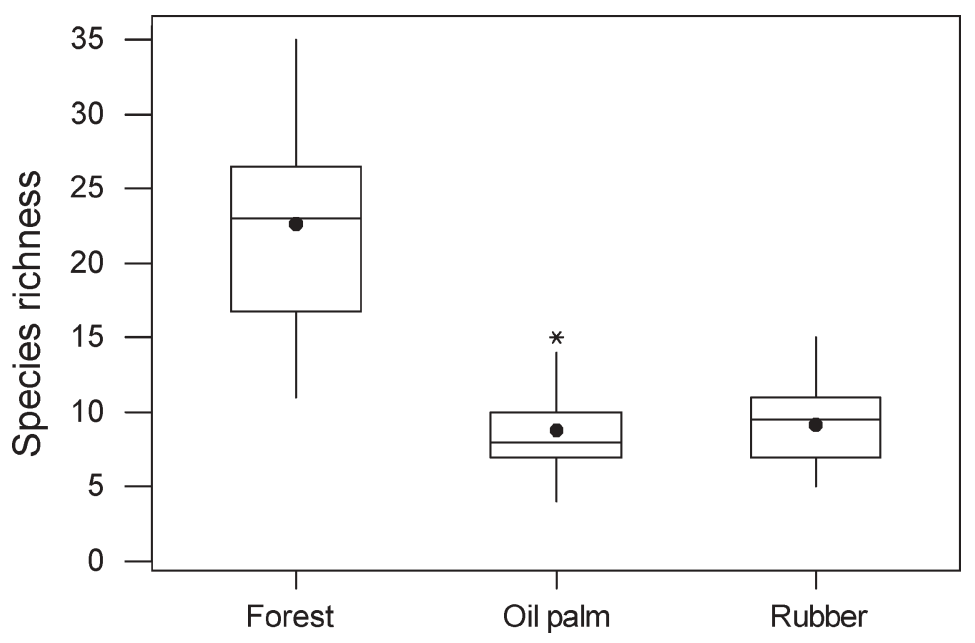

Figure 3. Boxplot of cumulative species richness recorded over two 20-minute observation periods in forest, oil palm and rubber. The horizontal line represents the median, the box the interquartile range and the vertical lines span the range of the values lying between the interquartile and 1.5 times the interquartile range. Outliers beyond this are represented by asterisks. The mean is represented by a dot. GLMs indicated that the means differed significantly $\left(\mathrm{F}_{2,87}=114.5, P<0.0001\right)$.

underestimated, although having two count periods is likely to have reduced this bias in the final cumulative estimates of species richness.

Across all habitat types, 128 species were recorded (Table 1 ). The cumulative number of species recorded across the two counts at each point ranged from 4 to 35 (mean $=13.5, \mathrm{SE}=0.82)$. A total of 41 species was recorded in oil palm plantations, 41 in rubber plantations and 108 in forest. Four species (3\% of all species recorded) were recorded only in oil palm plantations, 6 species $(5 \%)$ only in rubber and 77 species $(60 \%)$ only in forest. Mean species richness per point was significantly higher in 


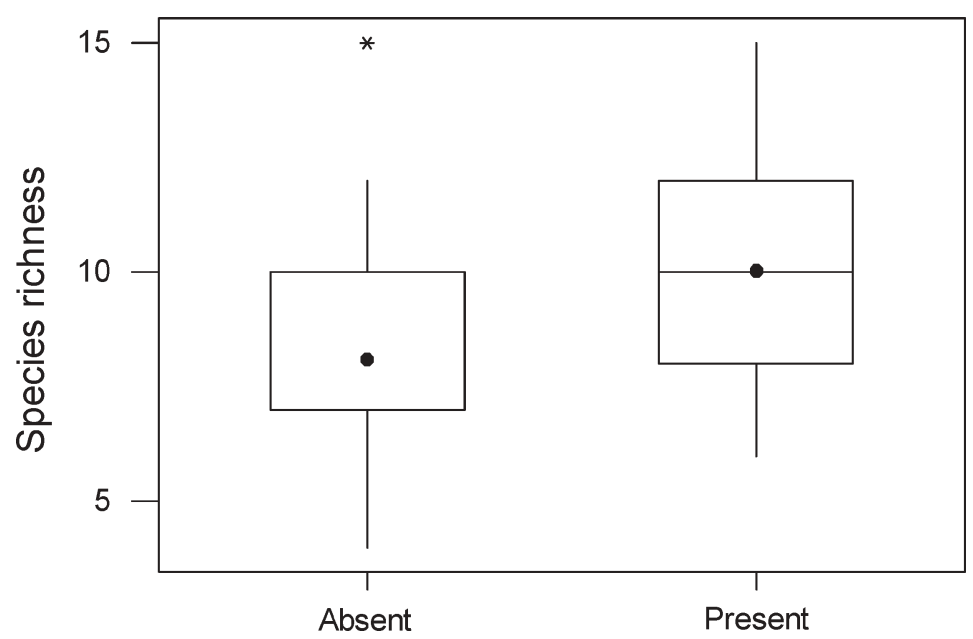

Figure 4. Boxplot of species richness in oil palm and rubber plantations in which undergrowth was present and absent. Interpretation of the boxplots is as in Figure 3. The median for the group "Absent" falls at the lower limit of the interquartile range. GLMs indicated that the means differed significantly $\left(\mathrm{F}_{1,58}=9.94, P<0.002\right)$.

forest $(22.6, \mathrm{SE}=1.04)$ than in rubber $(9.1, \mathrm{SE}=1.07)$ or oil palm plantations $(8.8, \mathrm{SE}$ = 1.07; Figure 3). Insectivores and frugivores tended to suffer relatively greater losses, both in terms of species richness and overall abundance, than species with mixed diets (Table I).

Within plantations, species richness did not differ significantly between oil palm and rubber, between plantations less than $1 \mathrm{~km}$ from forest and those further away, or between young and mature plantations $(P>0.1$ in all cases). Species richness in plantations in which a layer of undergrowth was allowed to develop (10.04, SE = 1.05) was significantly higher than in plantations with no undergrowth (8.09, SE = 1.05; Figure 4). Species recorded only in forest had significantly smaller ranges than species occurring in both forest and plantations or plantations alone (Figure 5). There was no significant difference in body size between species recorded only in forest and those recorded in plantations. However, species that were recorded in both forest and plantations had smaller body size than species recorded only in forest (MannWhitney $U$-test, $P=0.001$ ).

Of the 16 Globally Threatened or Near-Threatened species recorded (BirdLife International 2000), only one was recorded outside forest. The eight species listed by Round and Treesucon (1996) as being confined to extreme lowland areas were also recorded only in forest. The distribution of bird species by family is shown in the Appendix; groups well represented in forest but absent or poorly represented in plantations included woodpeckers, barbets, broadbills, leafbirds and babblers.

The mean relative abundance of species occurring in both forest and plantations did not differ significantly between the two habitat types (Mann-Whitney $U$-test, $P>$ o.I). Mean species relative abundance did not differ significantly between oil palm and rubber. Species composition and abundance were extremely similar in oil palm and rubber plantations, and there was a highly significant positive correlation between mean relative abundances in each plantation type across the 51 species recorded in 


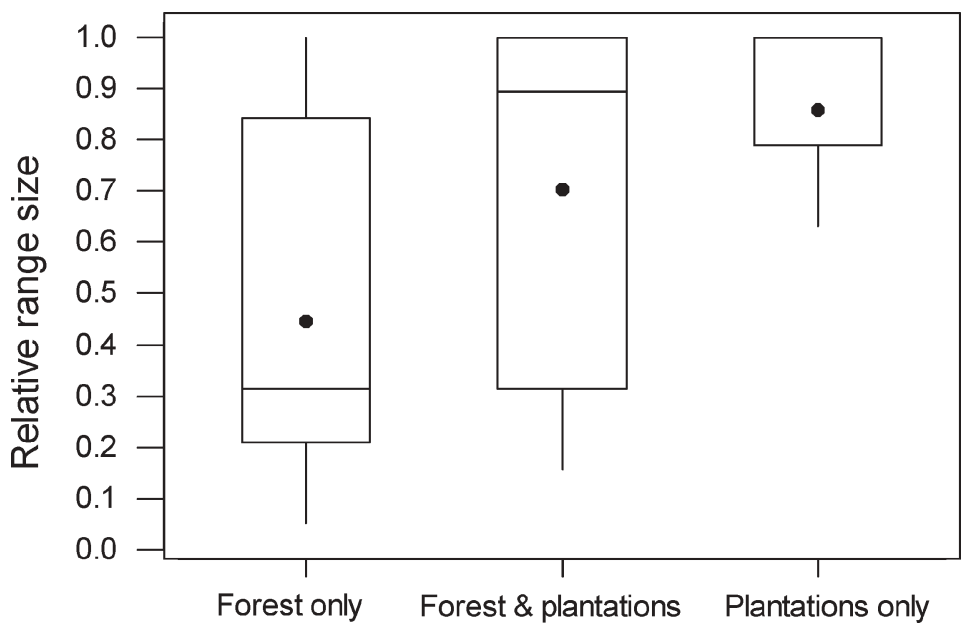

Figure 5. Relative range sizes in Thailand of species recorded only in forest $(n=68)$, only in plantations $(n=17)$ or both $(n=26)$. Non-breeding species were excluded. There was a significant difference between the three groups of species (Kruskal-Wallis test, adjusted for ties; $H=$ $27.9, \mathrm{df}=2, P<0.0001$ ). In pairwise tests, species occurring only in forest had significantly smaller national ranges than species occurring only in plantations or species occurring in both, which did not differ significantly from each other. Interpretation of the boxplots is as in Figure 3. The median for the "Plantations only" group falls along the upper limit of the interquartile range.

at least one plantation type (Figure 6). Communities in both plantation types were numerically dominated by just two or three species.

\section{Discussion}

The results indicate that conversion of forest to commercial plantations of oil palm or rubber results in two major changes to bird communities: the replacement of speciesrich communities with species-poor communities, and the replacement of threatened and range-restricted species by species of lower conservation concern and with extensive ranges. The combination of these processes means that forest conversion to plantations represents a severe threat of biodiversity, with the resulting habitats supporting communities dominated by a small number of common and widespread species. Almost all species of conservation concern disappeared following forest conversion to plantations. These patterns match results of work undertaken in a number of agricultural systems in different parts of the world (e.g. Pomeroy and Dranzoa 1997, Waltert et al. 2004) and appear to have some generality across regions and agricultural systems (Donald 2004).

The demand for agricultural products, including palm oil and rubber, is likely to increase in line with an increasing world population, representing probably the greatest single threat to the world's birds (BirdLife International 2004). Palm oil production is expected to double between 2004 and 2020. A gradient of options exists to meet this demand, ranging between the extremes of meeting all needs by expanding the area of land covered by low-intensity agriculture (the "wildlife-friendly farming" option of 


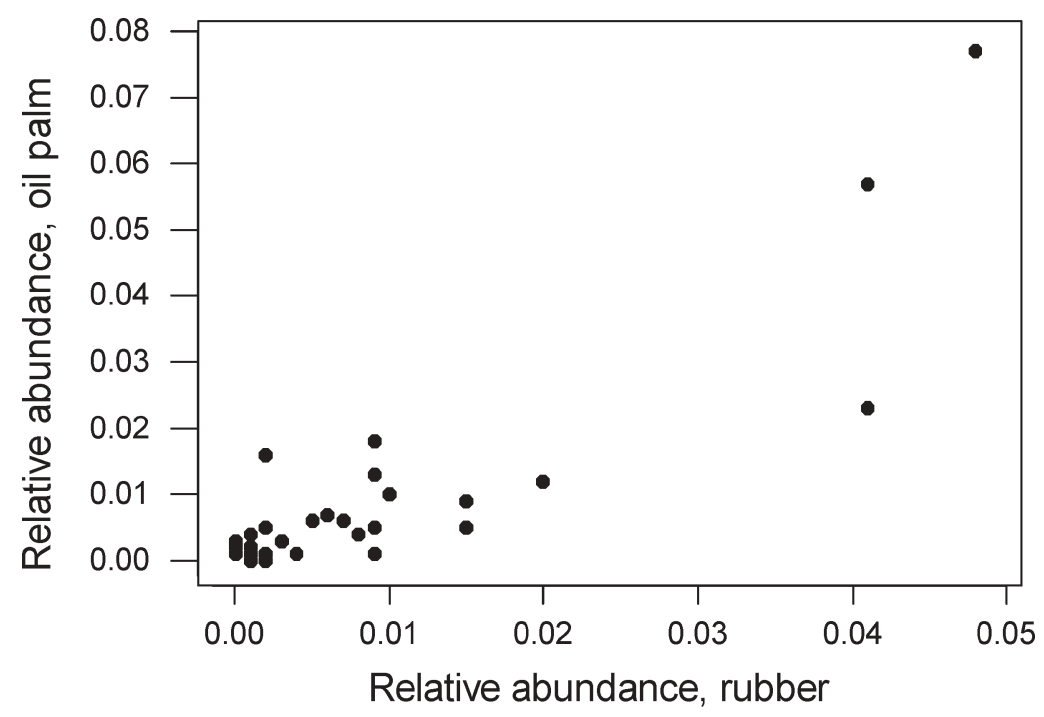

Figure 6. Mean relative abundance $(\lambda)$ in oil palm and in rubber plantations for each of the 51 species recorded in one or both plantation types. The two were significantly correlated $(r=0.88$, $n=51, P<0.0001$ ).

Green et al., 2005) to maximizing yield and keeping the area of land under production to a minimum ("land sparing"). Determining the point along this gradient that has the minimum impact on biodiversity requires consideration of the responses of different species to different levels of agricultural intensity (Green et al. 2005). In South-East Asia, almost all oil palm and rubber plantations are in the form of intensive monocultures (Clay 2004), and there is little history in the region of sympathetic agroforestry systems, such as are found in some rubber production systems in Indonesia (Joshi et al. 2003) and Brazil (Schroth et al. 2003). Oil palm and rubber production strategies in South-East Asia are not commercially conducive to low-intensity mixed agroforestry systems (Clay 2004). There therefore appear to be few opportunities to reduce the biodiversity impacts of these crops by increasing biodiversity in plantations. The bird communities in the structurally very different rubber and oil palm plantations were found to be remarkably similar at all stages of crop development, suggesting that planting a mixture of crops or age groups would have few positive effects on species richness in agricultural landscapes. Allowing undergrowth to develop under the crop did result in a significant, albeit small, increase in species richness. This increase was, however, wholly insufficient to compensate for the loss of species following forest conversion.

Given the lack of management options within plantations, it would appear that protecting pristine habitats and reducing the need to clear new land by maximizing yield within existing systems ("land sparing") would appear to be more efficient strategies than trying to increase the biodiversity value of plantations through methods such as those reviewed by Hartley (2002). So far, increases in palm oil production have been brought about largely by increasing the area over which it is grown, and yields per unit area have remained relatively stable over the last decade; in Malaysia, the area planted increased by over 70\% between 1994 and 2004, whereas yield increased over 
the same period by less than $1 \%$. However, yields can be greatly increased through selective breeding and by developing hybrid crosses between African and American palm species; the yield of oil palm in Costa Rica, for example, is 3 times the global average (Clay 2004). It seems inevitable that the only way to meet current palm oil production targets while still conserving some lowland forests in South-East Asia will be to increase yields. Conservationists may find themselves in the unexpected position of having to encourage the palm oil and rubber industries to intensify production and increase profitability in existing plantations, as they have done previously in low-intensity rubber systems (Joshi et al. 2003, Schroth et al. 2004). Such a strategy would need to be backed by increased protection for non-agricultural habitats (Niesten et al. 2004).

\section{Acknowledgements}

For help with fieldwork we thank Yotin Meekaeo, Malcolm and Sheena Davies and the staff of the Khao-Pra Bang-Kram Wildlife Sanctuary. For helpful comments on previous drafts we thank Nigel Collar, Dieter Hoffmann, Fiona Sanderson, Jo Phillips, Debbie Pain, Stuart Marsden and two anonymous referees.

\section{References}

Balmford, A. and Long, A. (1994) Avian endemism and forest loss. Nature 372: 623-624.

Bibby, C. J., Burgess, N. D., Hill, D. A. and Mustoe, S. H. (2000) Bird Census Techniques. Second edition. London: Academic Press.

BirdLife International (2000) Threatened Birds of the World. Barcelona and Cambridge, U.K.: Lynx Edicions and BirdLife International.

BirdLife International (2001) Threatened Birds of Asia: The BirdLife International Red Data Book. Cambridge, U.K.: BirdLife International.

BirdLife International (2004) State of the World's Birds 2004: Indicators for a Changing World. Cambridge, U.K.: BirdLife International.

Chung, A. Y. C., Eggleton, P., Speight, M. R., Hammond, P. M. and Chey, V. K. (2000) The diversity of beetle assemblages in different habitat types in Sabah, Malaysia. Bull. Entomol. Res. 90: 475-496.

Clay, J. (2004) World Agriculture and the Environment: A Commodity-by-Commodity Guide to Impacts and Practices. Washington, DC: Island Press.

Crawley, M. J. (2002) Statistical Computing: An Introduction to Data Analysis Using S-Plus. Chichester, U.K.: Wiley.

Danielsen, F. and Heegaard, H. (1995) Impact of logging and plantation development on species diversity: a case study from Sumatra. Pp. 73-92 in Ø. Sandbukt, ed. Management of Tropical Forests: Towards an Integrated Perspective. Oslo: Centre for Development and the Environment, University of Oslo.

Donald, P. F. (2004) Biodiversity impacts of some agricultural commodity production systems. Conserv. Biol. 18: 17-38.

Fogden, M. P. L. (1971) The seasonality and population dynamics of equatorial forest birds in Sarawak. Ibis 114: 307-343.

Freeman, S. N., Pomeroy, D. E. and Tushabe, H. (2003) On the use of Timed Species Counts to estimate avian abundance indices in species-rich communities. African J. Ecol. 41: 337-348.

Gaston, K. J., Blackburn, T. M., Greenwood, J. J. D., Gregory, R. D., Quinn, R. M. and Lawton, J. H. (2000) Abundance-occupancy relationships. J. Appl. Ecol. 37 (Suppl. 1): 39-59.

Green, R. E., Cornell, S. J., Scharlemann, J. P. W. and Balmford, A. (2005) Farming and the fate of wild nature. Science 307: 550-555. 
Gregory, R. D. \& Gaston, K. J. (2000) Explanations of commonness and rarity: separating resource use and resource availability in British breeding birds. Oikos 88: 515-526.

Hartley, M. J. (2002) Rationale and methods for conserving biodiversity in plantation forests. Forest Ecol. Mgmt. 155: 81-95.

He, F. L., Gaston, K. J. and Wu, J. G. (2002) On species occupancy-abundance models. Ecoscience 9: $119-126$.

Ickes, K. (2001) Hyper-abundance of native wild pigs (Sus scrofa) in a lowland dipterocarp rain forest of peninsular Malaysia. Biotropica 33: 682-69o.

Joshi, L., Wibawa, G., Beukema, H., Williams, S. and van Noordwijk, M. (2003) Technological change and biodiversity in the rubber agroecosystem of Sumatra. Pp. 133-158 in J. H. Vandermeer, ed. Tropical Agroecosystems. Boca Raton, FL: CRC Press.

Lambert, F. R. and Collar, N. J. (2002) The future for Sundaic lowland forest birds: long-term effects of commercial logging and fragmentation. Forktail 18: 127-146.

Mayaux, P., Achard, F. and Malingreau, J.-P. (1998) Global tropical forest area measurements derived from coarse resolution satellite imagery: a comparison with other approaches. Environm. Conserv. 25: 37-52.

Niesten, E. T., Rice, R. E., Ratay, S. M. and Paratore, K., eds. (2004) Commodities and Conservation: The Need for Greater Habitat Protection in the Tropics. Washington, DC: Conservation International.

Pomeroy, D. and Dranzoa, C. (1997) Do tropical plantations of exotic trees in Uganda and Kenya have conservation value for birds? Bird Popul. 4: 23-36.

Robson, C. (2002) A Field Guide to the Birds of Thailand. London: New Holland Publishers.

Round, P. D. and Treesucon, U. (1996) Birds of Khao Nor Chuchi: Check-list and Guide to Bird Finding. Bangkok: Bird Conservation Society of Thailand.

Scharlemann, J. P. W., Green, R. E. and Balmford, A. (2004) Land-use trends in Endemic Bird Areas: global expansion of agriculture in areas of high conservation value. Global Change Biol. 10: 2046-2051.

Schroth, G., Coutinho, P., Moraes, V. H. F. and Albernaz, A. L. (2003) Rubber agroforests at the Tapajós River, Brazilian Amazonia: environmentally benign land use systems in an old forest frontier region. Agric. Ecosyst. Environm. 97: 151-165.

Schroth, G., Moraes, V. H. F. and da Mota, M. S. S. (2004) Increasing the profitability of traditional, planted rubber agroforests at the Tapajós river, Brazilian Amazon. Agric. Ecosyst. Environm. 102: 319-339.

Selmi, S. and Boulinier, T. (2004) Distribution-abundance relationship for passerines breeding in Tunisian oases: test of the sampling hypothesis. Oecologia 139: 440-445.

Tilman, D., Fargione, J., Wolff, B., D'Antonio, C., Dobson, A., Howarth, R., Schindler, D., Schlesinger, W. H., Simberloff, D. and Swackhamer, D. (2001) Forecasting agriculturally driven global environment change. Science 292: 281-284.

Waltert, M., Mardiastuti, A. and Mühlenberg, M. (2004) Effects of land use on bird species richness in Sulawesi, Indonesia. Conserv. Biol. 18: 1339-1346.

Wells, D. R. (1999) The Birds of the Thai-Malay Peninsula. London: Academic Press.

Williams, H. E. and Vaughan, C. (2001) White-faced monkey (Cebus capucinus) ecology and management in neotropical agricultural landscapes during the dry season. Rev. Biol. Trop. 49: 1199-1206.

Wong, M. (1986) Trophic organisation of understory birds in a Malaysian dipterocarp forest. Auk 103: 100-116.

Wu, Z. L., Liu, H. M. and Liu, L. Y. (2001) Rubber cultivation and sustainable development in Xishuangbanna, China. Int. J. Sustain. Dev. World Ecol. 8: 337-345.

\section{SIRIRAK ARATRAKORN}

Bird Conservation Society of Thailand, 43 Soi Chokchai Ruammitr, Vibhavadee Road, Dindaeng, Bangkok 10320, Thailand. 
SOMYING THUNHIKORN

National Parks, Wildlife and Plant Conservation Department, 61 Phahonyothin Road, Ladyaow, Jatuchak, Bangkok 109oo, Thailand.

PAUL F. DONALD*

Royal Society for the Protection of Birds, The Lodge, Sandy, Bedfordshire SG19 2DL, U.K. E-mail:paul.donald@rspb.org.uk

${ }^{*}$ Author to whom correspondence should be sent.

Received 22 March 2005; revision accepted I June 2005

Appendix. Taxonomic breakdown of species recorded in forest and in plantations of oil palm and rubber, listing number of species recorded in forest and plantations by bird family. Taxonomy follows the Sibley and Monroe classification

\begin{tabular}{lcc}
\hline Family & Forest $(n=30)$ & Plantations $(n=60)$ \\
\hline Turnicidae & 0 & 1 \\
Picidae & 4 & 0 \\
Megalaimidae & 5 & 0 \\
Trogonidae & 1 & 0 \\
Coraciidae & 0 & 1 \\
Halcyonidae & 1 & 1 \\
Alcedinidae & 1 & 0 \\
Meropidae & 1 & 0 \\
Cuculidae & 5 & 3 \\
Centropidae & 1 & 1 \\
Psittacidae & 1 & 0 \\
Caprimulgidae & 0 & 1 \\
Columbidae & 2 & 1 \\
Charadriidae & 0 & 1 \\
Accipitridae & 1 & 1 \\
Ardeidae & 1 & 1 \\
Pittidae & 2 & 0 \\
Eurylamidae & 4 & 0 \\
Irenidae & 3 & 0 \\
Pardalotidae & 0 & 1 \\
Laniidae & 1 & 0 \\
Corvidae & 15 & 4 \\
Muscicapidae & 9 & 4 \\
Sturnidae & 0 & 1 \\
Pycnonotidae & 12 & 7 \\
Cisticolidae & 0 & 1 \\
Sylviidae & 19 & 7 \\
Nectariniidae & 13 & 1 \\
Passeridae & 3 & $\mathbf{1 9}$ \\
No. of families represented & $\mathbf{2 2}$ &
\end{tabular}

